\title{
Efficacy of Indigenous Bubble CPAP in Neonates with Respiratory Distress
}

\author{
Keludeppa Talawar ${ }^{1}$, Ramesh Pattar ${ }^{1}$, Bhuvaneshwari Yelamali ${ }^{2}$, Raghavendra Vanaki ${ }^{3}$ \\ ${ }^{1}$ Assistant Professor, Department of Paediatrics, SN Medical College, Bagalkot, Karnataka, ${ }^{2}$ Professor and Head, Department of Paediatrics, SN Medical College, Bagalkot, \\ Karnataka, ${ }^{3}$ Associate Professor, Dept. of Paediatrics, SN Medical College, Bagalkot, Karnataka.
}

\section{Abstract}

Background: Respiratory distress in newborn due to varied aetiology is one of the common causes for new born admission to NICU, new born morbidity and mortality. Bubble CPAP is a simple, cost effective and gentle mode of respiratory support in newborns with respiratory distress. It reduces the need for mechanical ventilation in appropriately selected cases. In this paper we review our institute experience of using very low cost indigenous CPAP as primary way of respiratory support and its outcome. Objectives: Effectiveness of indigenous CPAP as a low cost measure in treatment of respiratory distress in newborn period and its outcome. Design: Prospective observational study. Subjects and Methods: This study included 100 consecutive both term and preterm newborns admitted for respiratory distress due to varied aetiologies like respiratory distress syndrome, transient tachypnea of newborn, apnea of prematurity, birth asphyxia, meconium aspiration syndrome, etc in our NICU over a period of 1 year. Exclusion criteria being babies put on CPAP for post-extubation respiratory distress and babies with severe life threatening surgical conditions. Downe's scoring for term and Silvermann's scoring for preterm babies were used to assess the severity of respiratory distress and also to assess the response to indigenous CPAP. Results: Out of 100 newborns with respiratory distress treated with indigenous CPAP, $73 \%$ improved, $21 \%$ were further put on mechanical ventilation and $6 \%$ were discharged against medical advise. Failure of CPAP was associated with co morbidities like sepsis, congenital heart diseases, PPHN and IVH. Conclusion: Indigenous bubble CPAP is low cost equipment (Total cost Rs.301) effective in treatment of respiratory distress in newborn at resource limited neonatal intensive care units where newborn admissions are in excess.

Keywords: Continuous positive airway pressure (CPAP), Indigenous CPAP, Respiratory distress (RD), Low cost.

Corresponding Author: Dr. Raghavendra Vanaki, Associate Professor, Department of Paediatrics, SN Medical College, Bagalkot, Karnataka.

Received: September 2019

Accepted: September 2019

\section{Introduction}

Respiratory distress in newborn is the most common indication for neonatal intensive care unit admission. The varied aetiologies being respiratory distress syndrome, apnea of prematurity, transient tachypnea of newborn, pulmonary infections, meconium aspiration syndrome etc. Restoration of functional residual capacity of lung using positive pressure is one of the pillars of respiratory distress treatment. ${ }^{[1]}$ Continuous positive airway pressure (CPAP) is a way of applying positive air way pressure during the respiratory cycle of a spontaneously breathing patient. ${ }^{[2]}$ This can be achieved by using non-invasive technique like bubble CPAP. Bubble CPAP is a non-invasive mode of respiratory assistance in sick neonates. Buckmaster, et al, ${ }^{[3]}$ showed that earlier application of CPAP might reduce further need of mechanical ventilation and its adverse outcome like Broncho-pulmonary dysplasia.

In this present study the objective was to evaluate the outcome of indigenous bubble CPAP as a treatment modality in new born babies with respiratory distress of varied aetiology. In his study Pooniya $\mathrm{V},{ }^{[4]}$ highlighted that In regions where cost is a major factor hindering the treatment mode, inexpensive indigenously assembled bubble
CPAP device is beneficial in terms of reducing morbidity and mortality. In a set up which treats large number of neonates, where cost plays a major role, having many company made bubble CPAP is not feasible. Even though indigenous bubble CPAP is not superior to regular bubble CPAP, it's low cost, simple technique and good outcome makes it acceptable mode of treatment. (Intercostal drainage tube-Rs. $81+$ Nasal Cannula-Rs. $120+3$-way cannula-Rs. $100=$ Rs.301total cost) The total cost for assembled indigenous bubble CPAP is Rs 300-350 per case which is considerably low compared to the charges of conventional ventilator derived CPAP and stand alone bubble CPAP machines.

\section{Subjects and Methods}

This study was carried out using locally designed nasal CPAP circuit. Paediatric faculty, residents and nursing staff were briefed about the circuit, its functioning, indications and monitoring of new born.

The Nasal CPAP System: The nasal CPAP system consists of three major components, a continuous oxygen flow into the circuit, an expiratory limb to create positive end expiratory pressure is immersed into water and the nasal prongs which connect neonatal airway to circuit. 
The locally designed circuit was as follows, oxygen blender was connected to oxygen and compressed air for supplying appropriate concentration of oxygen for inspiration. Flow rate 5-8 liters/minute was set by using flow meter. This in turn was connected to humidifier. The pressure in the bubble CPAP system was generated by placing the distal expiratory tubing in water by using intercostal drainage bag as a pressure generator. The length of the tubing immersed determines the required pressure. Patient interface: short and wide nasal prongs are used as the nasal interface between the neonate's airway and the circuit. These prongs allow a low resistance to air flow.

This study was carried out on neonates admitted to NICU of a tertiary care center at a district place in a low socio economic area. Study included 100 consecutive both term and pre term newborns admitted for respiratory distress due to varied causes like respiratory distress syndrome, transient tachypnea of new born, apnea of prematurity, birth asphyxia, meconium aspiration syndrome, etc. The indications for starting nasal CPAP were presence of increased work of breathing, supra and sub-sternal retractions, nasal flaring and grunting. Also in babies who are unable to maintain oxygen saturation $(\mathrm{Spo} 2<85 \%)$ even after oxygen supplementation. Exclusion criteria being babies put on CPAP for post-extubation respiratory distress, severe life threatening surgical conditions and in those babies where parent consent was not given. The following parameters like respiratory rate, heart rate, $\mathrm{SpO} 2, \mathrm{BP}, \mathrm{CFT}$, peripheral pulses, urine output and $\mathrm{ABG}$ were monitored continuously by residents while newborn was on CPAP. Downe's scoring for term and Silverman's scoring for preterm were used to assess the severity of respiratory distress and also to assess the response to indigenous CPAP. Those babies in whom scoring is not satisfactory were further put on mechanical ventilation.

\section{Results}

Over a period of 1 year, 100 consecutive both term and preterm newborns admitted to our NICU for respiratory distress who met inclusion criteria were put on indigenous nasal CPAP were observed and studied. Out of 100 newborns, $67 \%$ were male and $33 \%$ were female babies. $30 \%$ newborns weighed $<1.5 \mathrm{~kg}, 36 \%$ between $1.5-2.5 \mathrm{~kg}$, $32 \%$ between $2.5-3.5 \mathrm{~kg}$ and $2 \%$ of newborns weighed $>$ $3.5 \mathrm{~kg}$. [Table 1]

The most frequent indication for CPAP was Respiratory distress syndrome in $32 \%$ followed by Birth asphyxia in $28 \%$, Meconium aspiration syndrome in $11 \%$, Transient tachypnea of newborn in $8 \%$, Apnea of prematurity $8 \%$ and Congenital heart disease in $2 \%$ of the cases studied.[Table 2] Out of these 100 cases $73 \%$ improved, $21 \%$ needed mechanical ventilation further and $6 \%$ were discharged against medical advise.

Mean duration of CPAP was $56.4+25$ hours. Mean Downe's score for neonates who improved was $4.98+0.83$ and who failed CPAP was 6.12+0.99.

Failure of CPAP was associated with co-morbidities like Sepsis, Congenital heart diseases, PPHN and IVH.

Table 1: Distribution of babies on Indigenous bubble CPAP according to birth weight.

\begin{tabular}{|l|l|l|l|l|}
\hline $\begin{array}{l}\text { Weight in } \\
\text { kgs }\end{array}$ & Improved & $\begin{array}{l}\text { Mechanical } \\
\text { ventilation }\end{array}$ & DAMA & Total \\
\hline$\leq 1.5 \mathrm{~kg}$ & $20(66.6 \%)$ & $8(26.6 \%)$ & $2(6.6 \%)$ & 30 \\
\hline $1.51-2.50 \mathrm{~kg}$ & $25(83.3 \%)$ & $8(22.2 \%)$ & $3(8.3 \%)$ & 36 \\
\hline $2.51-3.50 \mathrm{~kg}$ & $26(81.2 \%)$ & $5(15.6 \%)$ & $1(3.1 \%)$ & 32 \\
\hline$>3.5 \mathrm{~kg}$ & $2(100 \%)$ & 0 & 0 & 2 \\
\hline & 73 & 21 & 6 & 100 \\
\hline
\end{tabular}

Table 2: Distribution depending on diagnosis.

\begin{tabular}{|l|l|l|l|l|}
\hline Diagnosis & Improved & $\begin{array}{l}\text { Mechanical } \\
\text { ventilation }\end{array}$ & DAMA & Total \\
\hline RDS & $20(62.5 \%)$ & $9(28 \%)$ & $3(9.3 \%)$ & 32 \\
\hline BA & $20(71 \%)$ & $6(21.4 \%)$ & $2(7.1 \%)$ & 28 \\
\hline MAS & $8(72 \%)$ & $3(27.2 \%)$ & 0 & 11 \\
\hline TTNB & $8(100 \%)$ & 0 & 0 & 8 \\
\hline Sepsis & $9(81 \%)$ & $1(9 \%)$ & $1(9 \%)$ & 11 \\
\hline Apnea & $7(87 \%)$ & $1(12.5 \%)$ & 0 & 8 \\
\hline CHD & 0 & $1(50 \%)$ & $1(50 \%)$ & 2 \\
\hline
\end{tabular}

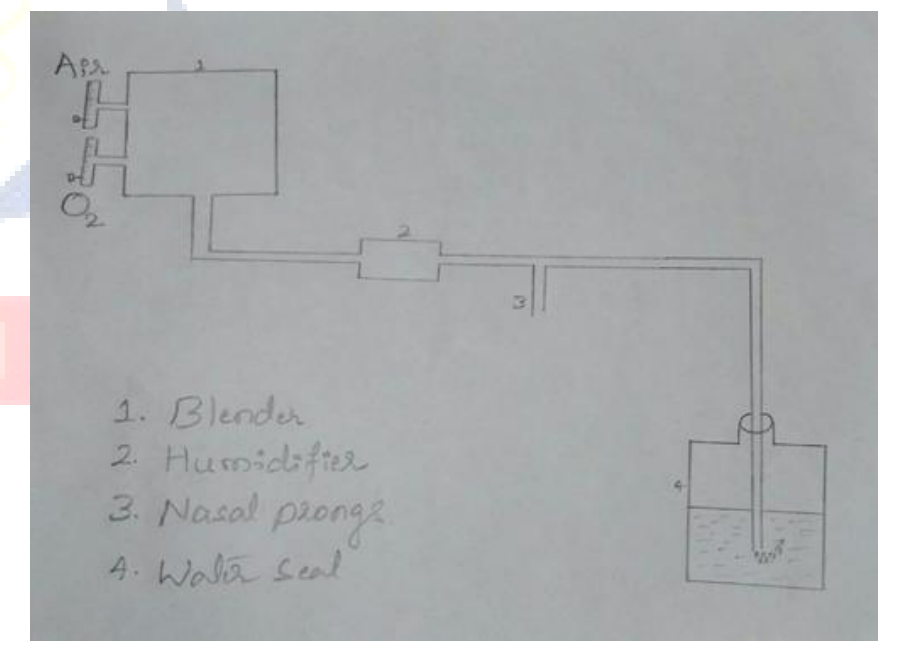

Figure 1: Circuit of Indigenous Bubble CPAP

\section{Discussion}

This study was undertaken to assess whether the indigenously assembled bubble CPAP was effective and life saving in the management of newborn with respiratory distress and their outcome.

This study demonstrates the potential impact of introducing a low cost, appropriate bubble CPAP system. The low cost indigenous bubble CPAP system we used was almost similar to that used in other studies by Charanjit Kaur et al, ${ }^{[5]}$ Shrestha et al ${ }^{[6]}$ Pooniya $\mathrm{V}$ et al ${ }^{[4]}$ Jain $\mathrm{H}$ et al. ${ }^{[7]}$

In our study common indication for bubble CPAP was respiratory distress syndrome $32 \%$, followed by birth asphyxia $28 \%$, MAS $11 \%$, TTNB $8 \%$, apnea of prematurity 
$8 \%$ and CHD $2 \%$. Other observation was $72 \%$ of meconium aspiration syndrome babies put on bubble CPAP survived which was similar to observation done by Jain $\mathrm{H}$ et al. ${ }^{[7]}$ Out of 100 cases $73 \%$ improved, $21 \%$ further required mechanical ventilation and $6 \%$ were discharge against medical advise. Regarding the outcome of CPAP, many studies have shown lower mortality and morbidity rate in infants with birth weight greater than 1500 gm who were put on CPAP compared to those managed on mechanical ventilation. $^{[8]}$

A study by Miller D et al showed benefits of non invasive mechanical ventilation. ${ }^{[9]}$ In their study the survival rates for RDS babies put on bubble CPAP was $67-83 \%$, in our study $62 \%$ of babies having RDS survived on bubble CPAP.

In a news review Vanpée $M$ et al shared their view on CPAP. They opined that the major risk for chronic lung disease is the need for mechanical ventilation, the strategy of early CPAP might result in reduced incidence of CLD. ${ }^{[10]}$ Various other studies have shown infants who were managed with bubble CPAP alone had better survival rates and decreased incidence of chronic lung disease and IVH. The total cost for assembled indigenous bubble CPAP is Rs 300-350 per case which is considerably low compared to the charges of conventional ventilator derived CPAP and stand alone bubble CPAP machines. It plays a very important role in reducing morbidity and mortality in new born with respiratory distress.

\section{Conclusion}

An Indigenously assembled low cost Bubble CPAP could play a crucial role in saving the lives of many neonates in resource restricted and low socio economic areas in India. The survival of neonates on Indigenous Bubble CPAP is significantly higher. Early initiation at physiological pressure is safe and reduces the need for mechanical ventilation.

Limitations of study: Sample size is less and comparative study between machine bubble CPAP and indigenous CPAP is needed.

1. Lack of larger sample size and randomization

2. lack of objective evaluation of cpap pressure delivered

3. inability to control and regulate accurately $\mathrm{FiO} 2$ delivered

\section{References}

1. Yagui AC, Vale LA, Haddad LB, Prado C, Rdssi FS, Deutsch AD, et al.Bubble CPAP versus CPAP with variable flow in newborns with respiratory distress: a randomized controlled trial. J Pediatr(Rio J). 2011;87(6):499-504.

2. Ambey R, Gogia P. Continuous positive airway pressure: The light that really does keep monster from baby away. Int J Pediatr Res Pract. 2015;1(1):3-6.

3. Buckmaster AG, Arnolda G, Wright IM. Continuous positive airway pressure therapy for infants with respiratory distress in non tertiary care centers: a randomized, controlled trial. Pediatr. 2007;120:509.

4. Pooniya V. Management of neonatal respiratory distress syndrome by indigenous CPAP in a resource poor setting. J Pediatr Care. 2015;1:1.

5. Kaur C, Sema A, Beri R, Puliyel JM. A simple circuit to deliver bubbling CPAP. Indian Pediatr. 2008;45:312.

6. Shrestha M, Basnet S, Shrestha PS. Bubble CPAP in neonatal unit of TUTH. J Nepal Paeditr Society. 2010;30(1):64-8.

7. Jain H, Arya S, Mandloi R, Menon S. To study the effectiveness of indigenous bubble CPAP in management of respiratory distress in newborns. Int J Pediatr Res. 2016;3(5):291-4.

8. Ho JJ, Subramaniam P, Henderson-Smart DJ, Davis PG. Continuous distending pressure for respiratory distress syndrome in preterm infants. Cochrane Database of Systematic Reviews 2002, Issue 2. Art. No.: CD002271. DOI: 10.1002/14651858.CD002271.

9. Millar D, Kirpalani H. Benefits of noninvasive ventilation. Indian Pediatrics. 2004;41:1008-1017.

10. Vanpée M, Walfridsson-Schultz U, Katz-Salamon M, Zupancic JAF, Pursley D, Jónsson B. Resuscitation and ventilation strategies for extremely preterm infants: a comparison study between two neonatal centers in Boston and Stockholm. Acta Paediatr. 2007 Jan;96(1):10-6.

Copyright: (C) the author(s), 2019. It is an open-access article distributed under the terms of the Creative Commons Attribution License (CC BY 4.0), which permits authors to retain ownership of the copyright for their content, and allow anyone to download, reuse, reprint, modify, distribute and/or copy the content as long as the original authors and source are cited.

How to cite this article: Talawar K, Pattar R, Yelamali B, Vanaki R. Efficacy of Indigenous Bubble CPAP in Neonates with Respiratory Distress. Asian J. Clin. Pediatr. Neonatol.2019;7(3):06-08.

DOI: dx.doi.org/10.21276/ajcpn.2019.7.3.2

Source of Support: Nil, Conflict of Interest: None declared. 